\title{
Bisphosfonate matrix metalloproteinase inhibitors for the treatment of periodontitis: An in vitro study
}

\author{
MARIANNA DE COLLI ${ }^{1}$, PAOLO TORTORELLA ${ }^{2}$, MARIANGELA AGAMENNONE $^{1}$, CRISTINA CAMPESTRE ${ }^{1}$, \\ FULVIO LOIODICE ${ }^{2}$, AMELIA CATALDI ${ }^{1}$ and SUSI ZARA $^{1}$ \\ ${ }^{1}$ Department of Pharmacy, University ‘G. d'Annunzio’ Chieti-Pescara, I-66100 Chieti; ${ }^{2}$ Department of \\ Pharmacy-Pharmaceutical Science, University ‘A. Moro’ Bari, I-70125 Bari, Italy
}

Received October 16, 2017; Accepted March 15, 2018

DOI: $10.3892 /$ ijmm.2018.3641

\begin{abstract}
Periodontitis is an inflammatory disease caused by anaerobic bacteria, including Porphyromonas gingivalis. Lipopolysaccharide (LPS)-stimulated persistent inflammation is responsible for an increase in matrix metalloproteinase (MMP) expression, resulting in periodontal tissue destruction. The aim of the present study was to investigate synthesized bisphosphonic MMP inhibitors, in an in vitro model consisting of human gingival fibroblasts exposed to LPS, and to compare the biological responses to those induced by zoledronate (ZA), a commercial bisphosphonate. MTT and lactate dehydrogenase (LDH) assays were used to measure cell viability and cytotoxicity, respectively. ELISA was performed to evaluate prostaglandin E2 $\left(\mathrm{PGE}_{2}\right)$, interleukin (IL)6 and collagen secretion, while western blotting was used to analyze MMP expression. No effect on viability and low cytotoxicity were observed following treatment with bisphosphonate compounds. In the present study, treatment with compound 1 did not increase the release of $\mathrm{PGE}_{2}$ and IL6. Increased levels of collagen I secretion were reported when compound 3 and ZA were administered. An increase of MMP8 was observed following ZA treatment, while a decrease of MMP9 and MMP14 following treatment with compounds 1, 2 and ZA were reported. The performance of compound 1 was optimal in terms of cell viability. Compound 1 also did not induce inflammation, and had the ability to counteract LPS-induced increases in MMP expression. These data suggested that compound 1 was the most suitable treatment to progress to an in vivo animal study, with the aim to confirm its use for the treatment of periodontitis.
\end{abstract}

Correspondence to: Ms Susi Zara, Department of Pharmacy, University 'G. d'Annunzio' Chieti-Pescara, 31 Via dei Vestini, I-66100 Chieti, Italy

E-mail:s.zara@unich.it

Key words: bisphosphonate, human gingival fibroblast, lipopolysaccharide, metalloproteinases, periodontitis, zoledronate

\section{Introduction}

Periodontitis is a chronic and frequent inflammatory disease that occurs due to an immune-inflammatory response to pathogenic subgingival microflora or to bacterial products, and is often responsible for loss of teeth in adults. In the presence of pathogenic oral bacteria, an altered host response is observed, leading to an augmented release of pro-inflammatory cytokines that results in chronic inflammation and progressive damage to soft and hard tooth-supportive structures (1). The majority of periodontal infections are provoked by Gram-negative, anaerobic bacteria, including Porphyromonas gingivalis, which serves a pivotal function in periodontal pathogenesis $(2,3)$. $P$. gingivalis releases large amounts of lipopolysaccharide (LPS), which constantly stimulates host cells and modulates the immune-mediated inflammatory response. The interaction between LPS and toll-like receptors (4) is known to lead to the activation of different pathways responsible for the production of pro-inflammatory cytokines, including interleukin (IL)-1 $\beta$ and tumor necrosis factor (TNF)- $\alpha$. The latter controls tissue remodeling under pathological conditions $(5,6)$. LPS structure is heterogeneous among different bacterial species, thus stimulating different immune responses in host cells $(6,7)$.

Matrix metalloproteinases (MMPs) are a large family of structurally-associated proteases, either expressed on the cell surface or secreted in extracellular space. They are characterized by a zinc-binding catalytic domain able to degrade several extracellular substrates $(8,9)$. MMPs, being able to degrade the majority of extracellular matrix and basement membrane components, are often classified according to their specific substrates as collagenases or gelatinases (9).

MMPs serve a pivotal function in the balance between the deposition and the degradation of the extracellular matrix in periodontal tissue in physiological and pathological conditions. In gingival crevicular fluid or in peri-implant sulcular fluid, it is thought to be an indicator of periodontal tissue health condition $(9,10)$.

Increased secretion of MMPs has been reported in chronic inflammatory conditions, including periodontitis, and leads to irreversible soft tissue destruction $(11,12)$. MMPs are synthetized in periodontal tissue when exposed to pathogenic bacteria, including $P$. gingivalis (3). Several studies have already suggested that the LPS is able to increase MMP 
expression in various types of cell, including human gingival fibroblasts (HGFs) (13).

As excessive production of MMPs is associated with several pathological processes, including cancer metastasis and chronic inflammatory conditions $(12,14)$, over the last 20 years the synthesis of a variety of low-molecular weight MMP inhibitors has occurred, even though the majority are not commercially available (15). MMP inhibitor structure is characterized by a peptidomimetic fragment, usually placed in the prime region of the active site, and a zinc-binding group (ZBG) able to coordinate the zinc ion. Hydroxamate is considered to be the most effective ZBG. However, hydroxamate inhibitors lack high specificity due to the presence of the hydroxamic group, which has scarce pharmacokinetic properties and is of toxicological consequence (16).

An attempt was made to overcome this issue by synthesizing novel inhibitors that do not contain the zinc binding group (17) or containing an alternative, more selective functional group coordinating the zinc ion (18-20). Novel bisphosphonic (BP) MMP inhibitors have been synthesized $(21,22)$ and their structural features include a BP group as the ZBG and an arylsulfonamide function that allows the correct positioning of the aryl portion in the MMP hydrophobic binding pocket. These compounds have been demonstrated to inhibit MMPs at nanomolar concentrations (21), and a number have been tested in vitro to analyse their activity on gingival fibroblasts, in comparison with zoledronate (ZA) (23). Furthermore, in a previous study, the effect of certain BPs on $P$. gingivalis growth and cytokine release by oral epithelial cells was evaluated (24).

Therefore, our group sought to test these compounds on human gingival fibroblasts (HGFs), exposed to LPS, in order to evaluate the biological response in terms of cell viability, cytotoxicity, inflammatory events and soft tissue destruction, in comparison with ZA, a commercially available bisphosphonic drug.

\section{Materials and methods}

Chemistry. Compounds 1, 2, 3 and zoledronic acid (Fig. 1) were synthesized as previously described in Rubino et al (21). The chemical characterization of studied compounds was as follows.

1-Hydroxy-2-(imidazol-1-yl)-ethylidene-1,1-bisphosphonic acid (ZA). Melting point (Mp): $220-3^{\circ} \mathrm{C} ; 1 \mathrm{H}$ NMR $\left(\mathrm{D}_{2} \mathrm{O}\right)$ : $\delta=4.49-4.56\left(\mathrm{~m}, 2 \mathrm{H}, \mathrm{NCH}_{2} \mathrm{C}\right), 7.21$ (s, $1 \mathrm{H}$, aromatic), 7.36, (s, 1H, aromatic), 8.56, (s, $1 \mathrm{H}$, aromatic); 31P NMR $\left(\mathrm{D}_{2} \mathrm{O}\right): \delta=14.83$ (br, 2P, PCP). Mass spectrometry (MS) [electrospray ionization (ESI)] m/z: 271 [M-H]-; MS2 m/z (\%): 189 (100).

(4-Nitro-phenylsulfonylamino)methyl-1,1-bisphosphonic acid (compound 1). Mp: $252^{\circ} \mathrm{C}$ (dec); $1 \mathrm{H} \mathrm{NMR} \mathrm{[(D6)DMSO]:}$ $\delta=3.78(\mathrm{td}, \mathrm{JHH}=9.6, \mathrm{JHP}=21.7,1 \mathrm{H}, \mathrm{PCHP}), 8.03-8.06$, 8.28-8.30 (m, 2H, 2H, aromatics), 8.32-8.53 (br, $4 \mathrm{H}, \mathrm{OH}$ and 1H, NH). 31P NMR [(D6)DMSO]: $\delta=14.59$ (d, JPH=21.3, 2P, PCHP); MS (ESI) m/z: 375 [M-H]-; MS2 m/z (\%): 357 ([M-H-H $\left.\mathrm{H}_{2} \mathrm{O}\right]-$, 100); Anal. calcd for $\left(\mathrm{C}_{7} \mathrm{H}_{10} \mathrm{~N}_{2} \mathrm{O}_{10} \mathrm{P} 2 \mathrm{~S} \cdot \mathrm{H}_{2} \mathrm{O}\right)$ : C $21.33 \%, \mathrm{H} 3.07 \%$, N 7.11\%, found: C $21.05 \%, \mathrm{H} 3.30 \%$, N $6.76 \%$.

(Biphenyl-4-sulfonylamino)methyl-1,1-bisphosphonic acid (compound 2). Mp: $236-7^{\circ} \mathrm{C} ; 1 \mathrm{H} \mathrm{NMR} \mathrm{[(D6)DMSO]:}$ $\delta=3.87$ (td, JHH=9.6, JHP=21.7, 1H, PCHP), 5.5 (br, 4H, OH and $1 \mathrm{H}, \mathrm{NH}), 7.37-7.51,7.69-7.77,7.88-7.91(\mathrm{~m}, 3 \mathrm{H}, 4 \mathrm{H}, 2 \mathrm{H}$ aromatics); 31P NMR [(D6)DMSO]: $\delta=15.12$ (d, JPH=21.3, 2P, PCHP); MS (ESI) m/z: 406 [M-H]-; MS2 m/z (\%): 388 (100); Anal. calcd for $\left(\mathrm{C}_{13} \mathrm{H}_{15} \mathrm{NO}_{8} \mathrm{P}_{2} \mathrm{~S} \cdot 3 / 2 \mathrm{H}_{2} \mathrm{O}\right): \mathrm{C} 35.95 \%, \mathrm{H} 4.18 \%, \mathrm{~N}$ $3.23 \%$, found: C $35.81 \%, \mathrm{H} 4.29 \%$, N $3.25 \%$.

(4'-Chloro-biphenyl-4-sulfonylamino)methyl-1,1-bisphosphonic acid (compound 3). Mp: $252^{\circ} \mathrm{C}$ (dec); $1 \mathrm{H}$ NMR [(D6) DMSO]: $\delta=3.86$ (td, JHH=9.6, JHP=21.7, 1H, PCHP), 7.32 (br, $4 \mathrm{H}, \mathrm{OH}$ and $1 \mathrm{H}, \mathrm{NH}), 7.52-7.55,7.72-7.77,7.88-7.91(\mathrm{~m}, 2 \mathrm{H}, 4 \mathrm{H}$, 2H, aromatics); 31P NMR [(D6)DMSO]: 15.04 (d, JPH=24.4, 2P, PCHP); MS (ESI) m/z: 442 [M+2-H]-, 440 [M-H]-; MS2 $\mathrm{m} / \mathrm{z}(\%)$ : 422 (100); Anal. calcd for $\left(\mathrm{C}_{13} \mathrm{H}_{14} \mathrm{C}_{1} \mathrm{NO}_{8} \mathrm{P}_{2} \mathrm{~S} \cdot 3 / 2 \mathrm{H}_{2} \mathrm{O}\right)$ : C $33.31 \%$, H $3.66 \%$, N $2.99 \%$, found: C $33.09 \%, \mathrm{H} 3.67 \%$, N $3.16 \%$.

Culture of HGFs. A total of 10 donors, periodontally and systemically healthy, subjected to the extraction of the third molar, signed their informed consent according to the Italian Legislation and in accordance with the code of Ethical Principles for Medical Research comprising Human Subjects of the World Medical Association (Declaration of Helsinki). The project obtained the approval of the Local Ethical Committee of the University of Chieti (Chieti, Italy; approval no. 1173, approved on 31/03/2016). Gingiva withdrawal and HGF culture was performed as previously reported by De Colli et al (23).

HGFs were cultured in high-glucose Dulbecco's modified Eagle's medium supplemented with $10 \%$ fetal bovine serum (Euroclone Spa, Pero, Italy) and $1 \%$ penicillin/streptomycin, and maintained at $37^{\circ} \mathrm{C}$ in a humidified atmosphere of $5 \%(\mathrm{v} / \mathrm{v})$ $\mathrm{CO}_{2}$. Once they reached confluence, all experimental groups were treated with $1 \mu \mathrm{g} / \mathrm{ml}$ LPS (InvivoGen, Inc., San Diego, CA, USA) for $24 \mathrm{~h}$ at $37^{\circ} \mathrm{C}$. Then, while maintaining the LPS in the cell medium, drugs 1-3 and ZA were solubilized in DMSO and administered to the HGFs at a final concentration of $100 \mu \mathrm{M}$ for each drug, for $72 \mathrm{~h}$ at $37^{\circ} \mathrm{C}$. The DMSO concentration in cell the medium was $<0.3 \%(0.136 \%)$ to exclude DMSO-mediated cytotoxicity (23).

MTT assay. HGF viability was evaluated after $72 \mathrm{~h}$ of treatment with $100 \mu \mathrm{M}$ BPs. The MTT assay was performed as previously reported by De Colli et al (23).

Cytotoxicity assays. HGF membrane integrity was assessed by measuring lactate dehydrogenase (LDH) leakage into the medium, using a CytoTox 96 non-radioactive cytotoxicity assay (Promega Corporation, Madison, WI, USA), following the manufacturer's protocol, after $72 \mathrm{~h}$ of culture under the different experimental conditions. Cytotoxicity was evaluated using the following formula: \% LDH released $=[(\mathrm{A}-\mathrm{B}) /(\mathrm{C}-\mathrm{B}) \times 100$, as reported by De Colli et al (23).

ELISA analysis of prostaglandin E2 (PGE $)$, IL6 and collagen type I secretion. $\mathrm{PGE}_{2}$, IL6 and collagen type I secretion in the culture medium at different experimental times was detected using ELISA kits, following the manufacturer's protocols. The amount of $\mathrm{PGE}_{2}$, IL6 and collagen type I was assessed using enzyme immunoassay kits for PGE ${ }_{2}$ and IL6 (Enzo Life Sciences, Inc., Farmingdale, NY, USA; cat. no. ADI-900-001 
<smiles>OC(P)(P)C(P)(P)Cn1ccnc1</smiles>

Zoledronate<smiles>O=P(O)(O)C(NS(=O)(=O)c1ccc(-c2ccccc2)cc1)P(=O)(O)O</smiles>

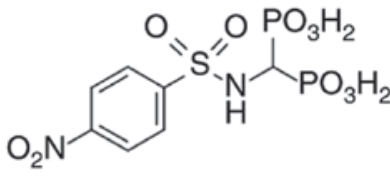

1<smiles>O=P(O)(O)C(NS(=O)(=O)c1ccc(-c2ccc(Cl)cc2)cc1)P(=O)(O)O</smiles>

Figure 1. Chemical structure of compounds 1,2,3 and zoledronate.

and ADI-900-033, respectively) and a human collagen type I ELISA kit (Cosmo Bio Co., Ltd., Tokyo, Japan; cat. no. ACE-EC1-E105-EX). The absorption values were obtained using a spectrophotometer (Multiskan GO; Thermo Fisher Scientific, Inc., Waltham, MA USA) at the following wavelengths: $405 \mathrm{~nm}$ for $\mathrm{PGE}_{2}$ and $450 \mathrm{~nm}$ for IL6 and collagen type I. PGE IL6 $^{2}$ and collagen type I secretion levels were measured in different wells and normalized for relative optical density (OD) values, as determined by the MTT assay, and expressed as $\mathrm{pg} / \mathrm{ml} / \mathrm{OD}$ MTT for $\mathrm{PGE}_{2}$ and IL6, and as $\mu \mathrm{g} / \mathrm{ml} /$ OD MTT for collagen type I (23).

Protein extraction and western blot analysis. HGFs were trypsinized and then centrifuged at $250 \mathrm{x}$ g for $10 \mathrm{~min}$ at $4^{\circ} \mathrm{C}$ to obtain pellets. Lysis buffer $(0.5 \mathrm{ml})$ containing protein inhibitors cocktail (PBS, 1\% IgePal CA-630, 0.5\% sodium deoxycholate, $0.1 \%$ SDS, $10 \mathrm{mg} / \mathrm{ml} \mathrm{PMSF}, 1 \mathrm{mg} / \mathrm{ml}$ aprotinin, $100 \mathrm{mM}$ sodium orthovanadate and $50 \mu \mathrm{g} / \mathrm{ml}$ leupeptin) was added to the cell pellets and set on ice for $30 \mathrm{~min}$. The lysed pellets were then re-suspended and kept on ice for a further $30 \mathrm{~min}$. Following centrifugation for $15 \mathrm{~min}$ at $20,000 \mathrm{x} \mathrm{g}$ at $4^{\circ} \mathrm{C}$, supernatants were collected as whole cell fractions. Protein concentration was determined using a Bicinchoninic Acid assay (QuantiPro ${ }^{\mathrm{TM}}$ BCA Assay kit for $0.5-30 \mu \mathrm{g} / \mathrm{ml}$ protein, cat. no. QPBCA-1KT; Sigma-Aldrich Merck KGaA, Darmstadt, Germany) according to the manufacturer's protocols. Total protein electrophoresis, nitrocellulose membrane transfer and blocking were performed as previously reported by De Colli et al (23). Briefly, total protein content $(30 \mu \mathrm{g})$ was electrophoresed via a 4-20\% SDS-PAGE and transferred to nitrocellulose membranes. Following blocking with 5\% non-fat milk, $10 \mathrm{mM}$ Tris- $\mathrm{HCl} \mathrm{pH} 7.5$ and $100 \mathrm{mM} \mathrm{NaCl}, 0.1 \%$ Tween-20 at room temperature for $1 \mathrm{~h}$, the nitrocellulose membranes were then probed overnight at $4^{\circ} \mathrm{C}$ with rabbit polyclonal anti-MMP-8 (cat. nos. sc-8782 and sc-50383, respectively; 1:200; Sigma Aldrich; Merck KGaA), anti-MMP9 and anti-MMP14 (cat. no. IM37; 1:1,000; Calbiochem; Merck KGaA; cat. no. orb166952; 1:200; Biorbyt Ltd., Cambridge, UK, respectively) primary antibodies, and mouse anti $\beta$-actin primary antibodies (cat no. A5616; 1:5,000; Sigma-Aldrich; Merck KGaA). Membranes were then washed in PBS and $0.1 \%$ Tween-20 three times for $10 \mathrm{~min}$ for each, and then probed for $1 \mathrm{~h}$ at room temperature with horseradish peroxidase-conjugated goat anti-mouse or goat anti-rabbit immunoglobulin G (cat. nos. 401253 and 401393, respectively; 1:20,000, Calbiochem; Merck KGaA), as previously described (23). Immunoreactive bands were detected using an enhanced chemiluminescence detection system (GE Healthcare Life Sciences, Little Chalfont, UK) and analyzed by densitometry. Densitometric values, expressed as integrated optical intensity, were estimated in a CHEMIDOC XRS system with QuantiOne 1-D analysis software (Bio-Rad Laboratories, Inc., Hercules, CA, USA). Values obtained were normalized based on densitometric values of internal $\beta$-actin.

Statistical analysis. Statistical analysis was performed using SPSS version 16.0 (SPSS, Inc., Chicago, IL, USA) and GraphPad Prism 5 software (GraphPad Software, Inc., La Jolla, CA, USA), and data were evaluated using one-way analysis of variance followed by the Student-Newman-Keuls post hoc test. The results were expressed as the mean \pm standard deviation. $\mathrm{P}<0.05$ was considered to indicate a statistically significant difference (25).

\section{Results}

Metabolic activity decreases when compounds 2, 3 and ZA are administered. The MTT assay revealed that all the compounds causes a statistically significant decrease of metabolic activity when compared with the LPS-treated sample. This reduction was particularly apparent in the LPS+ZA-treated sample, with respect to the samples treated with LPS and other compounds. Furthermore, treatment with compounds 2 and 3 significantly reduced HGF metabolic activity compared with the LPS+1-treated sample (Fig. 2).

Compounds 1, 2 and 3 , in contrast to ZA, preserve membrane integrity. To measure compound-induced cytotoxicity, the LDH assay was performed, revealing that LPS treatment induced relatively high LDH leakage. Treatment with compounds 1, 2 and 3 reduced LDH release compared with the LPS-treated group, while treatment with ZA increased LDH release compared with the LPS-treated group (Fig. 3).

Compound 1 does not contribute to inflammation. The secretion level of pro-inflammatory cytokine IL6 and the eicosanoid mediator $\mathrm{PGE}_{2}$ was assessed using ELISA assays, 


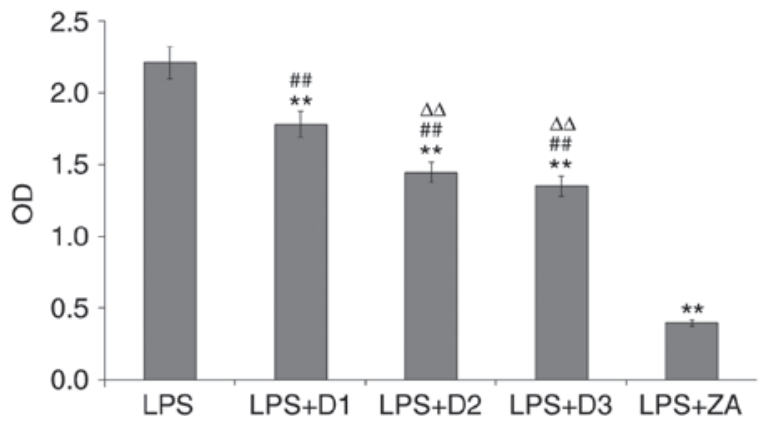

Figure 2. MTT assay in HGFs treated with LPS or LPS+compound 1, 2, 3 or ZA $(100 \mu \mathrm{M})$ for $72 \mathrm{~h}$. The graph represents the viability of HGFs as a percentage, expressed as relative to control cells (defined as 100). Data are presented as the mean \pm standard deviation of three separate experiments. ${ }^{* *} \mathrm{P}<0.01$ vs. $\mathrm{LPS},{ }^{\# \#} \mathrm{P}<0.01$ vs. $\mathrm{LPS}+\mathrm{ZA},{ }^{\Delta} \mathrm{P}<0.01$ vs. $\mathrm{LPS}+\mathrm{D} 1$. HGF, human gingival fibroblast; LPS, lipopolysaccharide; ZA, zoledronate; OD, optical density.

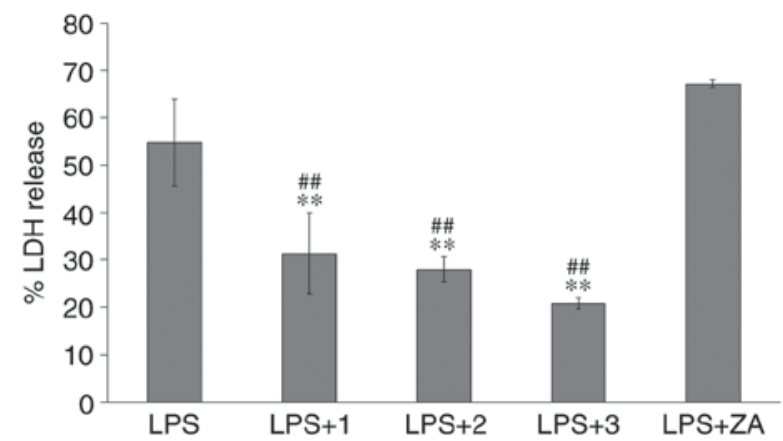

Figure 3. Cytotoxicity assay of human gingival fibroblasts treated with LPS or LPS+compound 1, 2, 3 or ZA $(100 \mu \mathrm{M})$ for $72 \mathrm{~h}$. LDH leakage is reported as the percentage of LDH leakage compared with the control. Data are presented as the mean \pm standard deviation of three separate experiments. ${ }^{* *} \mathrm{P}<0.01$ vs. LPS, ${ }^{\# \#} \mathrm{P}<0.01$ vs. LPS+ZA. LPS, lipopolysaccharide; ZA, zoledronate; $\mathrm{LDH}$, lactate dehydrogenase.

and a similar trend for these molecules was identified. The $\mathrm{PGE}_{2}$ secretion level is similar in the LPS+1-treated sample and the LPS-treated, while an increased level was recorded in the LPS+2, 3 and the ZA-treated samples, compared with the LPS-treated sample. In addition, there was a statistically significant increase in $\mathrm{PGE}_{2}$ secretion levels in the ZA-treated HGFs compared with all other experimental conditions;

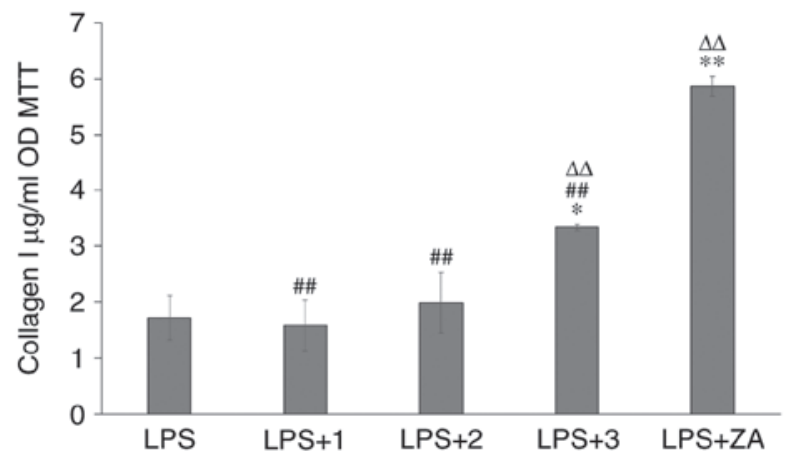

Figure 5. ELISA assay for collagen I secretion in human gingival fibroblasts treated with LPS or LPS+compound 1, 2, 3 or ZA $(100 \mu \mathrm{M})$ for $72 \mathrm{~h}$. Secretion levels are reported as $\mu \mathrm{g} / \mathrm{ml} / \mathrm{OD}$ MTT. Data are presented as the mean \pm standard deviation of three separate experiments. ${ }^{*} \mathrm{P}<0.05$ and ${ }^{* *} \mathrm{P}<0.01$ vs. LPS ${ }^{\# \#} \mathrm{P}<0.01$ vs. $\mathrm{LPS}+\mathrm{ZA},{ }^{\triangle} \mathrm{P}<0.01$ vs. LPS+D1. LPS, lipopolysaccharide; ZA, zoledronate; OD, optical density.

but $\mathrm{PGE}_{2}$ secretion decreased in HGFs treated with LPS+1 compared with LPS+2 and 3-treated samples (Fig. 4A). With regards to the IL6 secretion level, there was a significant increase in LPS+ZA-treated samples compared with other experimental groups, and a significant increase in IL6 secretion was also detected in the LPS+3-treated sample compared with the LPS+1-treated cells (Fig. 4B).

Treatment with compound 3 and ZA induces an increase of collagen I secretion in the cell culture medium. As collagen I represents the most abundant protein secreted by the HGFs, collagen I secretion was measured to evaluate cell adhesion and functionality. The ELISA assay revealed a statistically significant increase of protein secretion in the LPS+3 and ZA-treated samples compared with the LPS-treated samples, and a significant increase was identified in the LPS $+Z A$-treated samples compared with the LPS+1, 2, and 3-treated samples. A significant increase of collagen I secretion was observed in the LPS+3 and ZA-treated samples compared with the LPS+1-treated cells (Fig. 5).

Effects of treatment with ZA and compounds 1, 2 and 3 on MMPs. The expression of MMPs, the most important proteases involved in connective tissue remodeling, were also analyzed using western blotting. The inhibitive ability
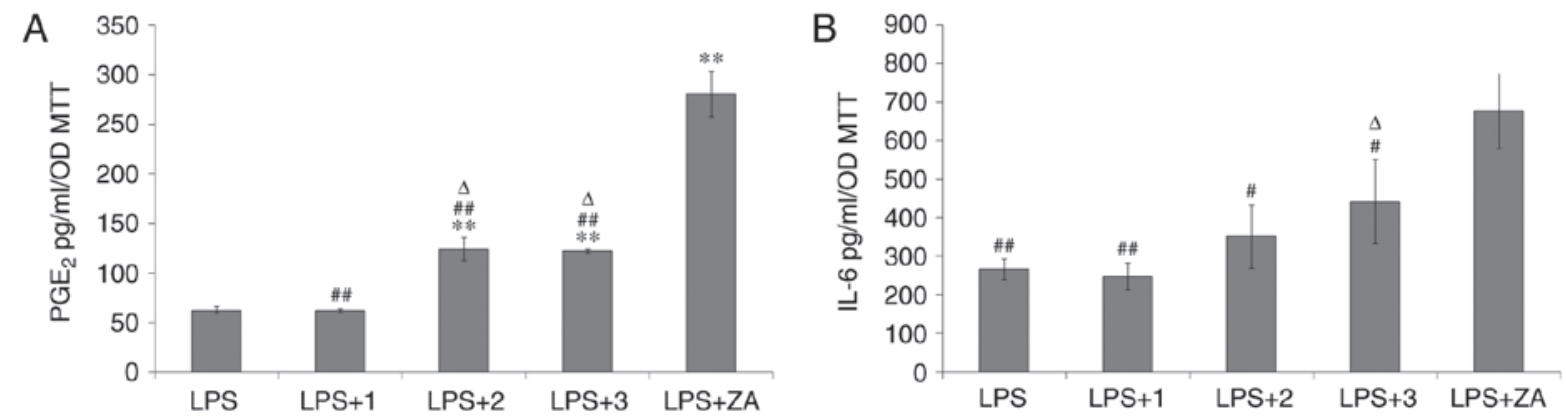

Figure 4. ELISA assay for (A) $\mathrm{PGE}_{2}$ and (B) IL6 secretion in human gingival fibroblasts treated with LPS or LPS+compound 1,2,3 or ZA (100 $\left.\mu \mathrm{M}\right)$ for $72 \mathrm{~h}$ Secretion levels are reported as $\mathrm{pg} / \mathrm{ml} / \mathrm{OD}$ MTT. Data are presented as the mean \pm standard deviation of three separate experiments. ${ }^{* *} \mathrm{P}<0.01$ vs. LPS, ${ }^{*} \mathrm{P}<0.05$ and ${ }^{\# \#} \mathrm{P}<0.01$ vs. LPS $+Z A,{ }^{\Delta} \mathrm{P}<0.05$ vs. LPS+D1. $\mathrm{PGE}_{2}$, prostaglandin E2; IL, interleukin; LPS, lipopolysaccharide; ZA, zoledronate; OD, optical density. 

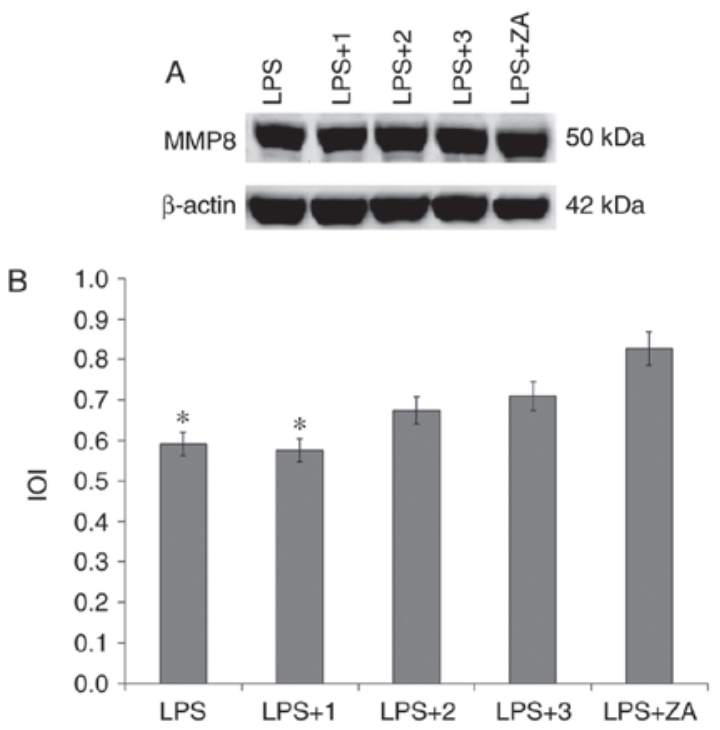

Figure 6. Western blot analysis of MMP8 expression in human gingival fibroblasts treated with LPS or LPS+compound 1, 2, 3 or ZA $(100 \mu \mathrm{M})$ for $72 \mathrm{~h}$. (A) The most representative gel images from three separate experiments are presented. (B) The histogram represents densitometric values as the mean \pm standard deviation, expressed as IOI. * $\mathrm{P}<0.05$ vs. LPS+ZA. MMP, matrix metalloproteinase; LPS, lipopolysaccharide; ZA, zoledronate; IOI, integrated optical intensity.

of novel synthesized BPs were analyzed using MPP-8, -9 and -14 (21). MMP8 expression was significantly augmented in the LPS+ZA-treated samples compared with the LPS and the LPS+1-treated samples (Fig. 6). MMP9 expression was significantly decreased in the LPS+1, 2 and ZA-treated samples compared with the LPS and the LPS +3-treated samples (Fig. 7A). The same trend was observed for MMP14 expression, which appears to significantly decrease in the LPS $+1,2$ and the ZA treated samples when compared with LPS and LPS+3-treated cells (Fig. 7B and C).

\section{Discussion}

Periodontitis is a common disease characterized by chronic microbial infection, which leads to chronic inflammation and damage to connective tissue and alveolar bone (26). Although $>600$ bacterial species have been identified in the oral cavity, previous studies have indicated that periodontitis is induced by the accumulation of Gram-negative bacteria in the dental biofilm, including $P$. gingivalis (27). The major periodontal pathogen $P$. gingivalis, and/or the LPS it releases, are known to be potent stimulators of inflammation (3). In parallel to inflammatory events, which are characterized by leukocyte activation and involvement, and also by the release of pro-inflammatory cytokines, an increase in MMP synthesis also contributes to periodontal tissue breakdown (8). At present, the mechanical removal of pathogenic bacteria and the administration of tetracyclines, traditionally considered inhibitors of MMPs (28), are considered effective interventions for the treatment of periodontitis.

Excessive production of MMPs is frequently associated with several pathological processes, including cancer metastasis and chronic inflammatory conditions $(12,14)$. Over the last 20 years, the synthesis of a variety of low-molecular weight MMP inhibitors has been promoted, even if the majority of these are not commercially available due to a lack of selectivity, pharmacokinetics and toxicological problems (29). An attempt was made to overcome this issue by synthesizing novel inhibitors with an improved selectivity profile. From a structural point of view, they are comprised of a BP group connected to the aryl portion through a sulfonamide linker. The bisphosphonate function was inspired by other clinically used compounds, including zoledronate; the aryl portion inserts in the specificity pocket of the enzymes that contribute to MMP selective inhibition, while the sulfonamide linker serves a crucial function in directing the aryl portion into the MMP hydrophobic selectivity pocket correctly. These
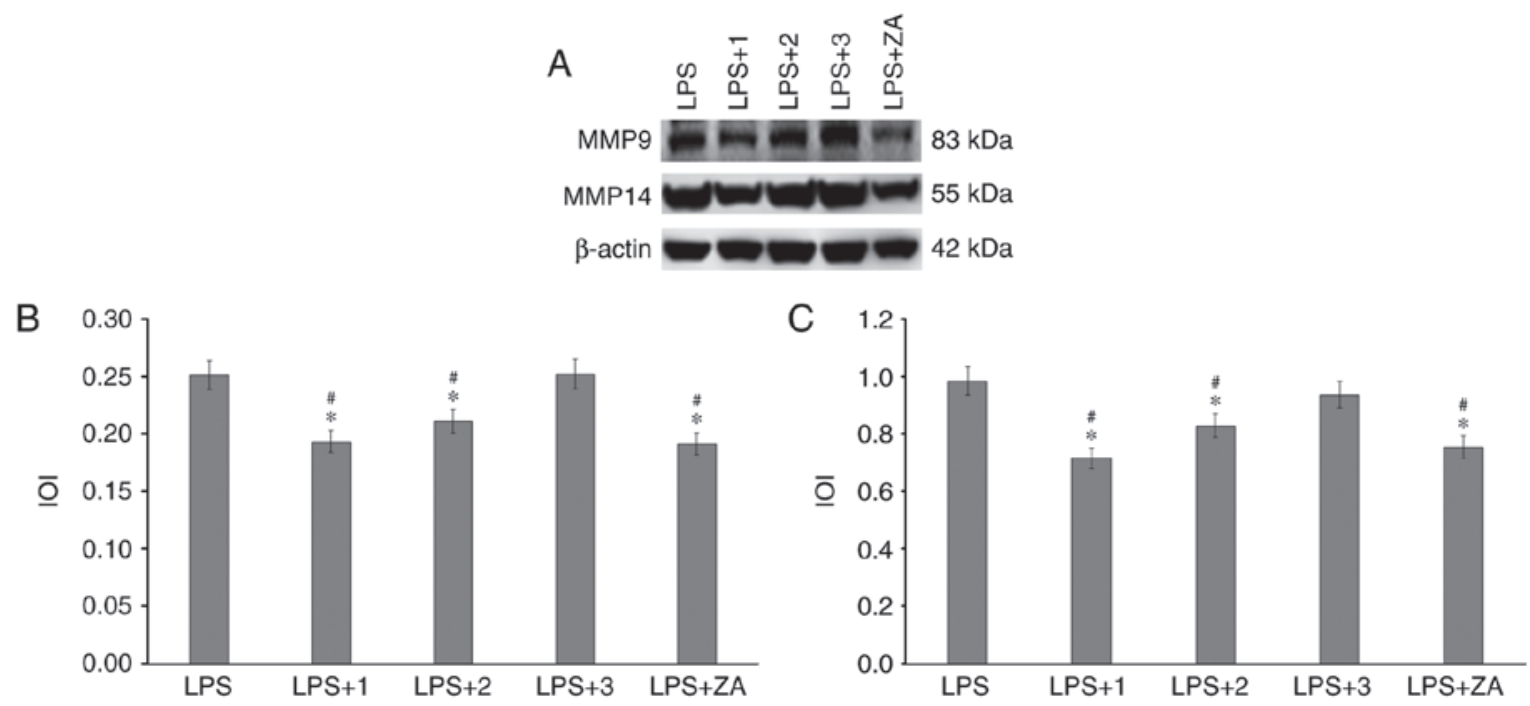

Figure 7. Western blot analysis of MMP9 and MMP14 expression in human gingival fibroblasts treated with LPS or LPS+compound 1, 2, 3 or ZA (100 $\mu$ M) for $72 \mathrm{~h}$. (A) The most representative gel images from three separate experiments are presented. The histograms represent densitometric values as the mean \pm standard deviation, expressed as IOI, for (B) MMP9 and (C) MMP14, respectively. "P<0.05 vs. LPS, "P<0.05 vs. LPS +3. MMP, matrix metalloproteinase; LPS, lipopolysaccharide; ZA, zoledronate; IOI, integrated optical intensity. 
molecules demonstrate MMP inhibitory activity at nanomolar concentrations $(21,22)$.

According to MMP inhibition ability and preliminary survival assay results, as reported in Rubino et al (21), three BP MMP inhibitors were selected and tested in an in vitro model consisting of HGFs exposed to $P$. gingivalis LPS, the most important factor in the pathogenesis of periodontal disease. The cells were then treated for $72 \mathrm{~h}$, while maintaining LPS exposure, with these BP compounds. The effects were compared with ZA, which is the most widely used BP drug with a chemical structure resembling that of the tested compounds.

As reported in previous studies, LPS stimulation is able to maintain high levels of cell viability $(30,31)$. The addition of compound 1 was demonstrated to be able to preserve this beneficial effect, allowing the maintenance of a high rate of cell viability throughout the treatment.

With regards to the evaluation of cytotoxic potential, the results of the present study highlighted the difference in effect between the novel synthesized compounds and ZA: All three novel molecules were able to restore HGF membranes integrity, which is compromised following LPS treatment; but membrane integrity still appeared damaged when the HGFs were exposed to ZA. This evidence is not surprising, as our group had reported it in previous studies $(23,32)$, and it was also reported in several other papers $(33,34)$ which clearly underline the ZA toxicity on a fibroblast population.

LPS is regularly used as an inflammatory stimulus in in vitro models, and the aim of the present study was to evaluate whether novel synthesized drugs would further induce the release of pro-inflammatory mediator, since the Toll-like receptor (TLR)4 signaling, triggered by LPS, leads to the production of inflammatory cytokines (30). Notably, when compound 1 was administered, there was no significant increase in inflammatory agents triggered by LPS treatment.

TLR receptors, stimulated by endogenous and exogenous ligands, including LPS, serve a pivotal role by triggering signaling pathways that culminate in inflammatory gene induction, leading to the accumulation of large amounts of collagen and other ECM proteins in gingival tissues (35). The model used in the present study demonstrated that collagen secretion in all the experimental groups was aligned with the release of pro-inflammatory cytokines. The results caused our group to hypothesize that MMP8 activity contributes to high levels of collagen I secretion, when compound 3 or ZA are administered. MMP8 is known to modulate ECM and non-matrix molecules and, in particular, is known for its ability to effectively degrade collagen type I. Furthermore, MMP8 is produced by different types of cell, including gingival fibroblasts, during various inflammatory diseases which include periodontitis $(36,37)$.

The involvement of MMPs in periodontal disease is well recognized as these proteins are synthesized in periodontal tissues in response to bacteria, including $P$. gingivalis, thus contributing to irreversible tissue destruction $(11,12)$. It is for this reason that research was extended to other MMP isoforms in the present study. Based on the results of the present study, treatment with compounds 1 and 2 was able to counteract the increase of MMPs recorded during periodontal disease and, notably, this effect was perfectly observed for MMP9 and 14
This ability is also attributed to ZA, however this may not be considered a useful drug in our experimental model as all other measured biological parameters clearly underlined the induction of cytotoxicity, suggesting poor tolerability. In addition, compound 3 was inadequate as a treatment in the present model of periodontitis, as it failed to solve the imbalance of connective tissue remodeling, as demonstrated by MMP expression.

For diseases characterized by altered matrix turnover, including periodontitis, compounds with the capability to inhibit MMPs may be useful, as these may restore the balance between matrix apposition and matrix degradation. In the present study, which utilized an in vitro model of periodontitis, compound 1 demonstrated the most optimal performance as it was able to maintain a high level of cell viability without significantly inducing the inflammatory response, counteracting the increase in MMP expression. In conclusion, compound 1 appears to be the most suitable treatment, and should be included in an in vivo animal study in order to confirm its use as a treatment for periodontitis, and to evaluate the pharmacokinetic profile of the molecule.

\section{Acknowledgements}

Not applicable.

\section{Funding}

The present study was supported by a Cataldi FAR Grant (2015) and a Zara FAR Grant (2015).

\section{Availability of data and materials}

The datasets used and/or analyzed during the current study are available from the corresponding author on reasonable request.

\section{Authors' contributions}

MDC performed the biological experiments, PT and MA synthetized and provided the compounds, $\mathrm{CC}$ performed the statistical analysis, FL realized the preliminary chemical test, AC coordinated the research project and SZ designed the experimental project. All authors read and approved the manuscript.

\section{Ethics approval and consent to participate}

The present study was approved by the Local Ethical Committee of the University of Chieti (Chieti, Italy; approval no. 1173 , approved on 31/03/2016). All donors provided written informed consent.

\section{Consent for publication}

Not applicable.

\section{Competing interests}

The authors declare that they have no competing interests. 


\section{References}

1. Laine ML, Crielaard W and Loos BG: Genetic susceptibility to periodontitis. Periodontol 2000 58: 37-68, 2012.

2. Darveau RP: Periodontitis: A polymicrobial disruption of host homeostasis. Nat Rev Microbiol 8: 481-490, 2010.

3. Herath TD, Wang Y, Seneviratne CJ, Lu Q, Darveau RP, Wang CY and Jin L: Porphyromonas gingivalis lipopolysaccharide lipid A heterogeneity differentially modulates the expression of IL-6 and IL-8 in human gingival fibroblasts. J Clin Periodontol 38: 694-701, 2011.

4. Park BS and Lee JO: Recognition of lipopolysaccharide pattern by TLR4 complexes. Exp Mol Med 45: e66, 2013.

5. Garcia de Aquino S, Manzolli Leite FR, Stach-Machado DR, Francisco da Silva JA, Spolidorio LC and Rossa C Jr: Signaling pathways associated with the expression of inflammatory mediators activated during the course of two models of experimental periodontitis. Life Sci 84: 745-754, 2009.

6. Martinho FC, Leite FR, Nóbrega LM, Endo MS, Nascimento GG, Darveau RP and Gomes BP: Comparison of Fusobacterium nucleatum and Porphyromonas gingivalis lipopolysaccharides clinically isolated from root canal infection in the induction of pro-inflammatory cytokines secretion. Braz Dent J 27: 202-207, 2016.

7. Darveau RP, Pham TT, Lemley K, Reife RA, Bainbridge BW, Coats SR, Howald WN, Way SS and Hajjar AM: Porphyromonas gingivalis lipopolysaccharide contains multiple lipid A species that functionally interact with both toll-like receptors 2 and 4 Infect Immun 72: 5041-5051, 2004.

8. Hannas AR, Pereira JC, Granjeiro JM and Tjäderhane L: The role of matrix metalloproteinases in the oral environment. Acta Odontol Scand 65: 1-13, 2007.

9. Sorsa T, Tjäderhane L, Konttinen YT, Lauhio A, Salo T, Lee HM, Golub LM, Brown DL and Mäntylä P: Matrix metalloproteinases: Contribution to pathogenesis, diagnosis and treatment of periodontal inflammation. Ann Med 38: 306-321, 2006.

10. Mäntylä P, Stenman M, Kinane DF, Tikanoja S, Luoto H, Salo T and Sorsa T: Gingival crevicular fluid collagenase-2 (MMP-8) test stick for chair-side monitoring of periodontitis. J Periodontal Res 38: 436-439, 2003.

11. Lagente V and Boichot E: Role of matrix metalloproteinases in the inflammatory process of respiratory diseases. J Mol Cell Cardiol 48: 440-444, 2010

12. Sorsa T, Tjäderhane L and Salo T: Matrix metalloproteinases (MMPs) in oral diseases. Oral Dis 10: 311-318, 2004.

13. Agarwal S, Misra R and Aggarwal A: Induction of metalloproteinases expression by TLR ligands in human fibroblast like synoviocytes from juvenile idiopathic arthritis patients. Indian J Med Res 131: 771-779, 2010.

14. Vincenti MP and Brinckerhoff CE: Transcriptional regulation of collagenase (MMP-1, MMP-13) genes in arthritis: Integration of complex signaling pathways for the recruitment of gene-specific transcription factors. Arthritis Res 4: 157-164, 2002.

15. Dufour A and Overall CM: Missing the target: Matrix metalloproteinase antitargets in inflammation and cancer. Trends Pharmacol Sci 34: 233-242, 2013.

16. Aschi M, Besker N, Re N, Pochetti G, Coletti C, Gallina C and Mazza F: Stereoselectivity by enantiomeric inhibitors of matrix metalloproteinase-8: New insights from molecular dynamics simulations. J Med Chem 50: 211-218, 2007.

17. Di Pizio A, Laghezza A, Tortorella $\mathrm{P}$ and Agamennone $\mathrm{M}$ : Probing the S1' site for the identification of non-zinc-binding MMP-2 Inhibitors. ChemMedChem 8: 1475-1482, 2013.

18. Campestre C,Tortorella P, Agamennone M,Preziuso S, Biasone A, Nuti E, Rossello A and Gallina C: Peptidyl 3-substituted 1-hydroxyureas as isosteric analogues of succinylhydroxamate MMP inhibitors. Eur J Med Chem 43: 1008-1014, 2008.

19. Campestre C, Agamennone M, Tauro M and Tortorella P: Phosphonate emerging zinc binding group in matrix metalloproteinase inhibitors. Curr Drug Targets 16: 1634-1644, 2015.
20. Giustiniano M, Tortorella P, Agamennone M, Di Pizio A, Rossello A, Nuti E, Gomez-Monterrey I, Novellino E, Campiglia P, Vernieri E, et al: Amino acid derivatives as new zinc binding groups for the design of selective matrix metalloproteinase inhibitors. J Amino Acids 2013: 178381, 2013.

21. Rubino MT, Agamennone M, Campestre C, Campiglia P, Cremasco V, Faccio R, Laghezza A, Loiodice F, Maggi D, Panza E, et al: Biphenyl sulfonylamino methyl bisphosphonic acids as inhibitors of matrix metalloproteinases and bone resorption. ChemMedChem 6: 1258-1268, 2011.

22. Tauro M, Loiodice F, Ceruso M, Supuran CT and Tortorella P: Dual carbonic anhydrase/matrix metalloproteinase inhibitors incur porating bisphosphonic acid moieties targeting bone tumors. Biooorg Med Chem Lett 24: 2617-2620, 2014.

23. De Colli M, Tortorella P, Marconi GD, Agamennone M, Campestre C, Tauro M, Cataldi A and Zara S: In vitro comparison of new bisphosphonic acids and zoledronate effects on human gingival fibroblasts viability, inflammation and matrix turnover. Clin Oral Invest 20: 2013-2021, 2016.

24. Zhao L, Marquis A, La VD, Agamennone M, Loiodice F, Tortorella P and Grenier D: Effects of biphenyl sulfonylamino methyl bisphosphonic acids on Porphyromonas gingivalis and cytokine secretion by oral epithelial cells. Med Chem 9: 855-860, 2013.

25. Ettorre V, De Marco P, Zara S, Perrotti V, Scarano A, Di Crescenzo A, Petrini M, Hadad C, Bosco D, Zavan B, et al: In vitro and in vivo characterization of graphene oxide coated porcine bone granules. Carbon 103: 291-298, 2016.

26. Stamatova I and Meurman JH: Probiotics and periodontal disease. Periodontol 2000 51: 141-151, 2009.

27. Picolos DK, Lerche-Sehm J, Abron A, Fine JB and Papapanou PN: Infection patterns in chronic and aggressive periodontitis. J Clin Periodontol 32: 1055-1061, 2005

28. Nip LH, Uitto VJ and Golub LM: Inhibition of epithelial cell matrix metalloproteinases by tetracyclines. J Periodont Res 28: 379-385, 1993.

29. Biasone A, Tortorella P, Campestre C, Agamennone M, Preziuso S, Chiappini M, Nuti E, Carelli P, Rossello A, Mazza F and Gallina C: Alpha-biphenylsulfonylamino 2-methylpropyl phosphonates: Enantioselective synthesis and selective inhibition of MMPs. Bioorg Med Chem 15: 791-799, 2007.

30. Wiktorowska-Owczarek A, Namiecińska M and Owczarek J: The effect of ibuprofen on BFGF, VEGF secretion and cell proliferation in the presence of lps in hmec-1 cells. Acta Pol Pharm 72: 889-894, 2015.

31. Xi ZD, Xie CY and Xi YB: Macrophage migration inhibitory factor enhances lipopolysaccharide-induced fibroblast proliferation by inducing toll-like receptor 4. BMC Musculoskelet Disord 17: 43, 2016.

32. De Colli M, Zara S, di Giacomo V, Patruno A, Marconi GD, Gallorini M, Zizzari VL, Tetè G and Cataldi A: Nitric oxide-mediated cytotoxic effect induced by zoledronic acid treatment on human gingival fibroblasts. Clin Oral Investig 19: 1269-1277, 2015

33. Açil Y, Möller B, Niehoff P, Rachko K, Gassling V, Wiltfang J and Simon MJ: The cytotoxic effects of three different bisphosphonates in-vitro on human gingival fibroblasts, osteoblasts and osteogenic sarcoma cells. J Craniomaxillofac Surg 40: e229-e235, 2012.

34. Anitua E, Zalduendo M, Troya M and Orive G: PRGF exerts a cytoprotective role in zoledronic acid-treated oral cells. Clin Oral Investig 20: 513-521, 2016.

35. Subramani T, Rathnavelu V, Alitheen NB and Padmanabhan P: Cellular crosstalk mechanism of Toll-like receptors in gingival overgrowth (Review). Int J Mol Med 35: 1151-1158, 2015.

36. Dejonckheere E, Vandenbroucke RE and Libert C: Matrix metalloproteinase 8 has a central role in inflammatory disorders and cancer progression. Cytokine Growth Factor Rev 22: 73-81, 2011.

37. Kiili M, Cox SW, Chen HY, Wahlgren J, Maisi P, Eley BM, Salo T and Sorsa T: Collagenase-2 (MMP-8) and collagenase-3 (MMP-13) in adult periodontitis: Molecular forms and levels in gingival crevicular fluid and immunolocalisation in gingival tissue. J Clin Periodontol 29: 224-232, 2002. 